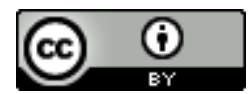

Esta obra está sob o direito de Licença Creative Commons Atribuição 4.0 Internacional.

\title{
GAMIFICAÇÃO: O JOGO DE TABULEIRO CONTRIBUINDO COMO INSTRUMENTO PARA O PROCESSO DE ENSINO-APRENDIZAGEM EM FISICA
}

\author{
Genivaldo Ferreira da Silva \\ Nailza Lima dos Santos ${ }^{2}$ \\ Pedro Juvêncio de Souza Júnior ${ }^{3}$
}

\section{RESUMO}

Este artigo explora o uso da gamificação no ensino de Física. O objetivo é apresentar e discutir, de forma abreviada, alguns mecanismos e práticas atuais sobre o tema. Aqui propomos a utilização de jogos de tabuleiro gigante para a dinâmica do ensino-aprendizagem em física através de metodologias ativas onde o aluno participa de forma abrangente e que lhes convenham a explorar os conteúdos de forma divertida através da competição. Atrelando tudo isso aos jogos de tabuleiro e aprender a ciência por traz da disciplina mais odiada pelos jovens estudantes que não simpatizam com ela. Propomos, pois, a ideia de jogo humano para explorar suas habilidades cognitivas. Visto que são nesses moldes que os jovens estão mais atrelados exigindo uma mudança exacerbada no contexto estudantil de aprender. O conceito emergente de gamificação que usa elementos do game e o game thinking para desenvolver processos inovadores para aprendizagem é introduzido e percebemos que tem trazido um rico e importante interesse dos alunos para a área das ciências. Assim, podemos perceber que o interesse dos alunos a interação proporcionadas pelos professores e alunos presente no dia do projeto proporcionou uma dinâmica que podemos torna-la acessível em todas a turmas do ensino médio

Palavras-chave: Educação Indígena. Currículo. Currículo na Educação Escolar Indígena.

\footnotetext{
${ }^{1}$ geni.herreira@gmail.com

2 nlima441@gmail.com

3 pedro.juvencio@ifal.edu.br
} 


\section{INTRODUÇÃO}

Entreter... Jogar... Tornar as aulas mais atraentes... Essas são frases ultimamente mencionadas por formadores em reuniões de formação de professores. A garotada está entretida nos jogos virtuais e estes estão inseridos no seu dia a dia e colaboram com a forma com que a geração “i” se comporta atualmente. Algumas vezes ainda é possível ouvir em sala de aula "Eu jogo free fire fessor" "eu já estou na rodada de ouro". Nessas falas vemos que os jovens estão cada dia mais atento aos aparelhos de smartphones, notebooks e tablet e é aí que a mudança de paradigma sobre o processo educacional aparece para que os professores se posicionem sobre as novas metodologias ativas, pois muitos deles não tem se atentado para isso, como discute FILHO et al (2020):

[...] "os educadores, que muitas vezes passaram por uma formação inicial através de uma metodologia predominantemente tradicional, ficam sem propostas diversificadas para aplicação em sala de aula. É muito comum suas aulas refletirem sua própria formação, que privilegiava o aluno "receptáculo". Assim, muitos destes professores, não obtêm êxito em promover nos alunos o interesse necessário para o aprendizado da Física e das Ciências. Sua prática continua empregando a metodologia memorística, com reforço do conhecimento através de fórmulas já prontas que são utilizadas na resolução de exercícios que se resumem a casos ideais sem conexão com o cotidiano e sem oportunidade para questionamentos" [...].

De acordo com GAROFALO (2018) "O principal objetivo deste modelo de ensino é incentivar os alunos para que aprendam de forma autônoma e participativa" onde a gamificacão e a utilização de jogos no ensino de ciências da natureza colaborem para o aprendizado do estudante. Completando o mesmo raciocino de Garofalo, NOEMI (2019) aponta que: “[...] compreender tais abordagens é algo fundamental para as escolas em vários sentidos. Primeiramente, na possibilidade de oferecer um ensino de qualidade e realmente igualitário a todos os estudantes. Em segundo lugar, em relação ao fato de que investir em tais métodos é um incrível diferencial competitivo, que demonstra interesse em mudanças e avanços variados [...].

Assim, percebemos que a geração conectada à internet apresenta o desinteresse atrelado com o conturbado avanço tecnológico e isso se justifica quando Silva et al (2019) aponta que: “ [...] os alunos contemporâneos já não são mais os mesmos para os quais o sistema educacional foi criado, as pesquisas apontam que o método tradicional de ensino, por si só, já não é mais capaz de atender as demandas desse aluno e ainda aponta a concentração de esforços no 
desenvolvimento de nova metodologias que visam o engajamento do estudante $[. .$.$] "$

A indústria de games está crescendo nos últimos anos e, contudo, os jovens estão cada vez mais engajado nesse mundo panorâmico dos games entretendo-se cada vez mais e fugindo da abordagem técnica de conhecimentos tradicionais não sentindo-se motivados para atividades escolares tradicionais que são entediantes e desinteressantes.

Silva et al (2019) ainda destacaram que a falta de motivação dos estudantes para aprender os conteúdos escolares abordados, não é um problema apenas do ensino de Física, mas da Educação Básica em geral e ainda podemos salientar com o que diz Andrade (2020) a respeito:

[...]Os estudantes de hoje são muito diferentes dos que a escola recebia no passado. Eles nasceram com a facilidade que a tecnologia trouxe, estão sempre conectados e têm mais acesso à informação. Por isso, os professores necessitam encontrar metodologias de ensino diferenciadas e modernas, capazes de despertar a motivação dos alunos, com aulas mais dinâmicas e interativas. Nesse sentido, as metodologias ativas propõem um eficiente modelo de ensinoaprendizagem, fazendo o uso de menos aulas expositivas e estimulando a autonomia do estudante, que passa a ser o protagonista na construção do seu conhecimento [...]. (imagine educação, 2020).
De fato, pois mesmo com todas as inovações propostas para o ensino e a busca e utilização de metodologias ativas não tem impactado os jovens e estes ainda anseiam por atividades que lhes coloquem no meio do processo de ensino-aprendizagem como argumenta Diniz (2020): “[...] é nesse viés que as metodologias ativas têm ganhado espaço na educação brasileira. Elas vêm para transformar os estudantes de meramente passivos e ouvintes para ativos e produtores de conhecimento [...]".

Ainda de acordo com Diniz (2020), existem 4 metodologias ativas para aplicar em sala de aula, quais sejam:

1. Sala de aula invertida - A sala de aula invertida é uma metodologia ativa, atual e moderna, que procura fazer do aluno ator principal de seu caminho rumo ao conhecimento.

2. Ensino Híbrido - é também uma metodologia ativa. Isso porque este ensino inovador busca unir de maneira equilibrada o ensino a distância e o ensino presencial.

3. Promoção de seminários e discussões Uma outra metodologia ativa superinteressante é a promoção de seminários e discussões. Mudar a disposição das carteiras e colocar alunos e professor em um mesmo patamar é bem interessante e faz os estudantes se sentirem importantes. 
4. Gamificação - é uma outra metodologia ativa. Ela busca trazer jogos para a sala de aula, e assim fazer dos celulares aliados na aprendizagem dos conteúdos das aulas. Porém, não somente utilizado celulares.

Neste contexto, optamos pela Gamificação e pensando nisso é que surge a ideia de propor a gamificacão no ensino de ciências da natureza para que seja proposta a interação dos estudantes, enfatizando o engajamento, melhoramento no desempenho e no rendimento dos estudantes. Silva \& Silva (2018) menciona a proposta de diferentes cenários e realidades simuladas, e ainda aponta que esse método ativo costuma ser utilizado para promover a imersão dos alunos em contextos específicos, exigindo-lhes raciocínio, planejamento e tomada de decisão.

Nesse trabalho foi avaliado os benefícios da gamificação no processo de ensino-aprendizagem de ciências da natureza durante aulas de Física com o uso de jogo gigante humano através da utilização do jogo de tabuleiro, com perguntas e respostas em turmas de ensino médio sendo proposto o projeto EXATAMENTE que se conectava a utilização do famoso jogo Furbica4. Portanto, Versões gigantes das atividades podem adicionar ludicidade e não limitam o projeto ao espaço da sala de aula.

\section{Os jogos de tabuleiro como estratégia metodológica no ensino de física}

Nossa metodologia é baseada na metodologia de projetos e que de acordo com Furquim (2019) esta também é conhecida como aprendizagem baseada em projetos, é desenvolvida por meio de trabalhos que partem da teoria à prática (ou até mesmo ao contrário), para que os alunos entendam melhor os conceitos abordados durante as aulas. Os projetos geralmente são em pequenos grupos ou envolvem a sala toda (podem até envolver turmas diferentes). Assim de acordo com Silva et al (2019), aplicar a gamificacão é como utilizar várias ferramentas dentro de uma caixa e que podem ser combinadas de diferentes maneiras, e para gamificar uma atividade não é necessário utilizar todos os elementos de games e que segundo McGonigal existem 4 elementos fundamentais em qualquer jogo: A voluntariedade, as regras, o objetivo e os feedbacks.

Conforme ilustrado na Figura 1, no processo de gamificacão os elementos devem estar interconectados onde a voluntariedade implica na aceitação das regras, objetivos e feedbacks. 
Figura 1 - Elementos fundamentais de um jogo

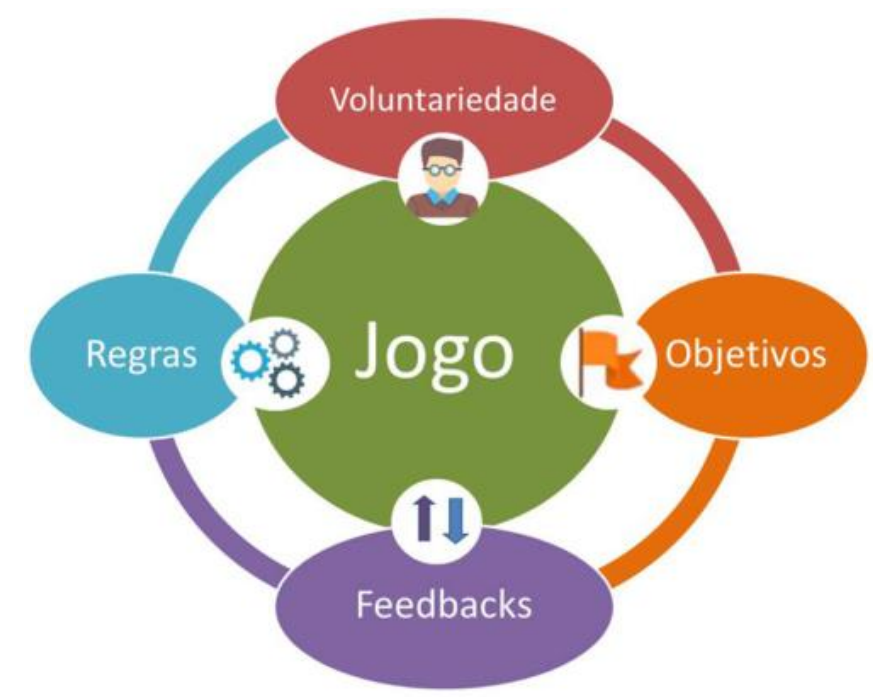

Fonte: https://www.scielo.br/pdf/rbef/v41n4/1806-9126-RBEF-41-4-e20180309.pdf

Regras: Todo jogo possui regras. São a base do processo e definem como deve ocorrer a interação, Feedback e evolução. Se bem construídas, são um excelente motivador. Interação ou Conflito/Competição/Cooperação: Todo processo de jogo é baseado em desafios que demandam superação, seja de si próprio, de companheiros ou de uma inteligência artificial.

Feedback: Todo jogador demanda informação constante de resposta do jogo acerca do seu desempenho. Feedback pode variar de recompensas a punições nos mais diferentes formatos e tem a finalidade de fazer o jogador continuar jogando.

Evolução: Também atua como motivador do jogo contínuo a evolução pode ser por níveis claros de dificultado ou evolução dentro de um objetivo (como jogos de tabuleiro).
Assim, Silva (2019) apud Castellar; Vilhena (2010) aponta sobre as possibilidades pedagógicas dos jogos, para o exercício cognitivo, afetivo, psicomotor e atitudinal dos alunos e a interação com o educador. E ainda acrescentamos o que diz Ferri; Soares (2015) apud Soares (2008) descrevendo “[...] que é importante os educadores buscarem alternativas que realmente alcancem os alunos contemporâneos, por meio de propostas de integrar os jogos ao ensino [...] pois, sabemos que precisamos de algo que realmente seja acessível aos interesses dos alunos e que os auxiliem a desenvolver a aprendizagem científica.

\section{O jogo}

Das populações nômades para a sala de aula, assim trata o artigo de Martins (2020) propondo que “A história do jogo de 
tabuleiro acompanha a humanidade desde as primeiras populações nômades, que talhavam seus próprios passatempos nas pedras de seus abrigos. Um gosto que rodou o mundo e que permite projetar um ano inteiro de aulas de História baseadas em tabuleiros como o Jogo Real de UR, da Mesopotâmia; o Senet, do Antigo Egito; o Latrúnculo, da Roma Antiga; o Xadrez Viking; A Raposa e os Gansos, da Idade Média; e o próprio Jogo da Onça".

As origens de Ludo, contudo, são bem antigas, pois por volta do século XV na Índia, existia um jogo parecido chamado "Chaupar", que mais tarde foi modificado dando origem a um jogo chamado "Pachisi" ou "Parcheesi", que possui tabuleiro e regras muito parecidas com Ludo, e que ao invés de dados utilizam-se conchas cujo resultado máximo é 25 (daí o nome do jogo, derivado da palavra Hindu "Paccís", que significa "vinte e cinco"). Em sua versão contemporânea, Ludo é um jogo clássico de regras fáceis, muito popular no Brasil, em que os jogadores movimentarão seus peões de acordo com o resultado do dado, tentando capturar ou barrar o avanço de seus adversários, ao mesmo tempo que movem suas peças tentando ser o primeiro a conseguir colocar todos os seus peões na casa final do tabuleiro.

O objetivo do jogo é ser o primeiro que, partindo de uma casa de origem, chega com quatro piões à casa final. Para isso, deve-se dar a volta inteira no tabuleiro e chegar antes dos adversários.

\section{Regras originais}

Cada jogador por sua vez lança um dado e faz avançar um dos seus peões em jogo o número de casas indicado. $\mathrm{O}$ seis permite colocar em jogo um peão que esteja na casa inicial ou fazer avançar um peão seis casas, e ainda um novo lançamento de dados. O número um também permite que o jogador tire o peão, mas é só o seis que permite $o$ jogador a lançar o dado novamente.

Quando o jogador entra com um peão na parte final, poderá completar o percurso somente se tirar o número de casas exato da casa final. Caso tire um número maior, o jogador entra e retrocede o número das casas que sobraram.

Não é permitido mais do que um peão em cada casa. Caso um peão venha a ocupar uma casa ocupada por um peão de outro jogador, o peão original regressará à casa inicial, é a chamada "captura" (coloquialmente, principalmente no Brasil, se usa o termo "comer"). É proibido capturar o adversário que está na casa de saída.

Quando dois peões de uma mesma cor se encontram em uma mesma casa, forma-se uma torre, impedindo outro peão de ocupar esta casa. Só poderá comer a torre 
com outra torre. Dois peões somente poderão caminhar como torre (ou seja, ambos juntos) caso haja uma torre no meio do caminho para ser "comida" uma vez que somente uma torre poderá comer outra, mandando os dois peões para casa inicial. Não havendo outra torre, e lançando o dado,

\section{Tabuleiro}

Existem quatro peões ou cavalos de cada cor (azul, verde, amarelo e vermelho) o tabuleiro tem a casa de saída logo após a parte final, como o peão (cavalo) não pode retroceder, é necessário dar outra volta.

o jogador deverá desfazer a torre, caminhando somente com um dos peões.

Figura 2 - Tabuleiro da furbica

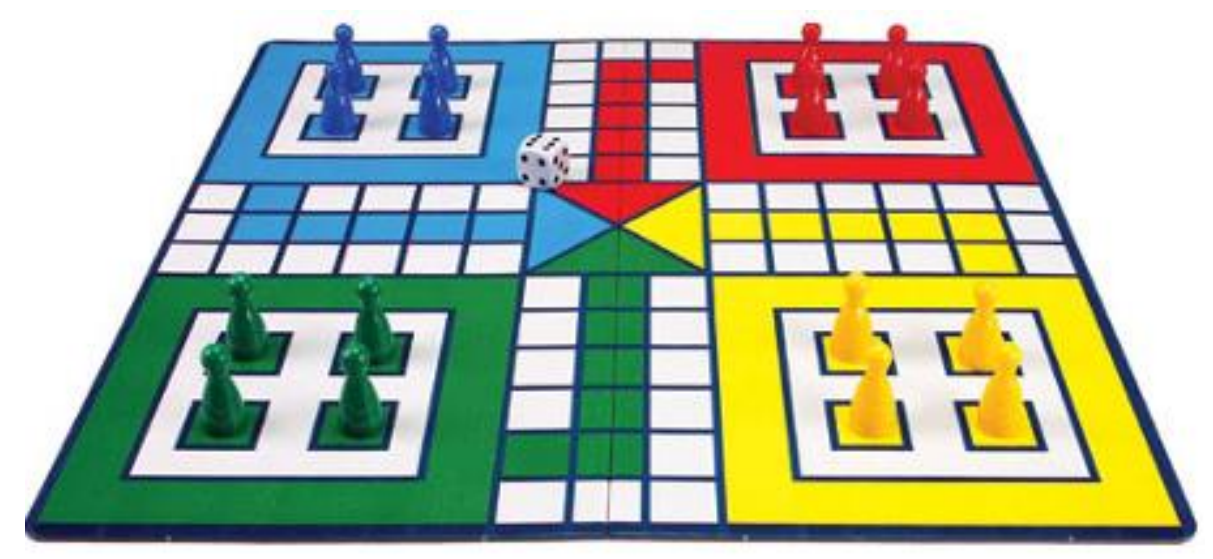

Fonte: http://www.tabuleirocriativo.com.br/post_ludo.html.

\section{METODOLOGIA}

Os jogos de tabuleiro permitem que as crianças e jovens desenvolvam atividades intelectuais e cognitivas de forma divertida, buscando estratégias para atingir um objetivo.

No projeto, intitulado Exatamente, procurou-se definir cada etapa do trabalho, para que os estudantes pudessem colhesselo e se familiarizasse com o tabuleiro pois alguns deles não o conheciam e não tinha jogado, assim por meio de objetivos grupais consolidamos treinamentos a priori para tal feito que estabelecessem um clima de cooperação.

Assim, apresentamos a proposta do jogo de tabuleiro para se trabalhar as disciplinas de ciências da natureza (Física, química e Biologia) em formato de projeto que envolvesse uma competição sendo os estudantes as peças do tabuleiro, justificando assim a ideia da Furbica humana.

Fizemos treinamento do jogo com os colegas com as tabuletas em sala de aula por um período de quinze dias. Após 
aprenderem a jogar com as regras do jogo propomos as novas regras que foram inseridas de acordo com a abordagem cientifica. Quais são:

\section{Início do jogo:}

1- Os líderes dos pinos jogam o dado para definir qual dos grupos deve iniciar a competição.

2- Os pinos só podem ser movidos pelos líderes quando jogar os dados e saírem os números 1 ou 6 respondendo à pergunta, se esta for dada como certa o pino avança a quantidade de casas que o dado de deslocamento define, do contrário voltara uma casa. Caso saia qualquer outro número diferente passa a vez, isso na primeira jogada diferenciando das demais caso já tenha saído algum pino que pode percorrer tranquilamente pelo trajeto.

3- CASAS DAS ESTRELAS - 13, 30, 47, 64: Caso os pinos sejam DERRUBADOS são banidos para suas respectivas zonas de início e se estes tiveres vidas adquiridas, voltam para as respectivas casas em que pegaram, que podem ser quaisquer umas destas. (obs.: somente pode pegar as vidas um membro da equipe); ( caso aconteça de dois pinos rivais se cruzarem no mesmo ponto o que detém a vida a perdera, ficando os dois no mesmo lugar).
4- No jogo constam perguntas de fisica, quimica, biologia, conhecimentos gerais de ciencias da natureza que os representantes das turmas (pinos), líderes, e alunos das turmas devem responder para prosseguir no trajeto do jogo ou caso as errem devem voltar 1 casa como punição.

5- Ao voltar a casa quando da resposta da pergunta errada, se algum pino estiver no lugar este será derrubado e se tiver outro no lugar este também deve sair e voltará a começar o jogo do início, caso tenha vida extra este deve volta para casa onde pegou tal vida, do contrário deve iniciar o jogo novamente com tal pino.

6- Se dois pinos da MESMA COR estiverem na mesma casa e outro de cor diferente parar na mesma casa os dois devem sair e voltar para o início do jogo, mas se algum deles tiver alguma vida extra este voltam para onde tenha pego.

7- Os integrantes de cada equipe que estejam fazendo o trajeto podem optar por errar a resposta para voltar a casa e derrubar o oponente como estratégia de jogo.

8- Durante o trajeto os componentes dos grupos nem da sala participante e nenhuma delas em hipótese alguma $N \tilde{A} O$ podem interferir nas respostas do aluno (escolhido pelo líder) sendo que cada pessoa que for 
responder terá a opção de RESPONDER OU NÃO A QUESTÃO, dando a mesma como errada fazendo o pino que esta sendo deslocado voltar uma casa dando como correta segue a sequência do item 2

9- Não necessariamente quem chegar no final do percurso será o vencedor, pois os grupos ainda terão que mostrar a proposta de projeto (seu respectivo relatório) que será apresentada no final do circuito que se caracterizara nas diversas modalidades: Projeto inovador, projeto reinventado, robótica, Aplicativos (computador ou celular). A comissão julgadora avaliará os trabalhos apresentados e darão uma pontuação referente ao mesmo dentro das categorias. Que valerá entre 5, 10, 15 e 20 pontos atribuídos pelos professores avaliadores para serem direcionados para feira de conhecimento 2019 caso sejam aprovados pela comissão organizadora dos professores credenciados.

10 - O grupo de jogadores (4 pinos) que chegar primeiro ao final do trajeto acumulara na $2^{\circ}$ fase um total de (100) pontos, o segundo grupo (75); o terceiro grupo (50) e o quarto grupo (25) para ser somado com a $1^{\circ}$ fase e $3^{\circ}$ Fase (que consiste na entrega dos relatórios dos distintos projetos científicos)

11- O jogador que tirar o número 6 no dado, tentar responder e errar a pergunta feita mesmo que por estratégia, passa a vez, sendo que este teria uma nova chance de jogada.

12- A casa portal (extremidades de cada casa/colorida) caso o peão caia nesta ele será transportado para extremidade a sua frente do outro lado do oponente, por exemplo, jogador verde em frente ao jogador vermelho e vice-versa.

Então partimos para um aquecimento prévio, aplicando ao jogo humano as novas regras para que os alunos tivessem ciências das mesmas e soubessem utiliza-las. Foram mostrados como funciona as regras do jogo de tabuleiro e também implementadas algumas que fossem relacionadas aos fenômenos físicos e químicos como por exemplo (o salto quântico) quando um dos estudantes poderia fazer tal feito quando de posse da casinha com essa regra.

\section{O projeto exatamente}

O Projeto surgiu com a ideia de propor o protagonismo juvenil e fazer com que os estudantes saíssem da rotina da sala de aula servindo como suporte para a interação entre as turmas e ao mesmo tempo se divertir com o conhecimento cientifico existente nas disciplinas.

Foram comprados e montados os moldes para composição do tabuleiro com 
pouco mais de 200 peças nas cores correspondentes as do jogo original.

Este projeto foi desenvolvido e aplicado aos estudantes da Escola estadual Professora Maria Avelina do Carmo no interior do estado de Alagoas visto que precisávamos interpolar a ideia de que as ciências físicas não eram tão tenebrosas com os alunos viam ou ouvia-se falar entre eles.

\section{Um aquecimento prévio realizado com os estudantes}

De fato, precisou-se fazer esse aquecimento prévio, pois alguns deles não imaginavam a dimensão que o jogo propunha.
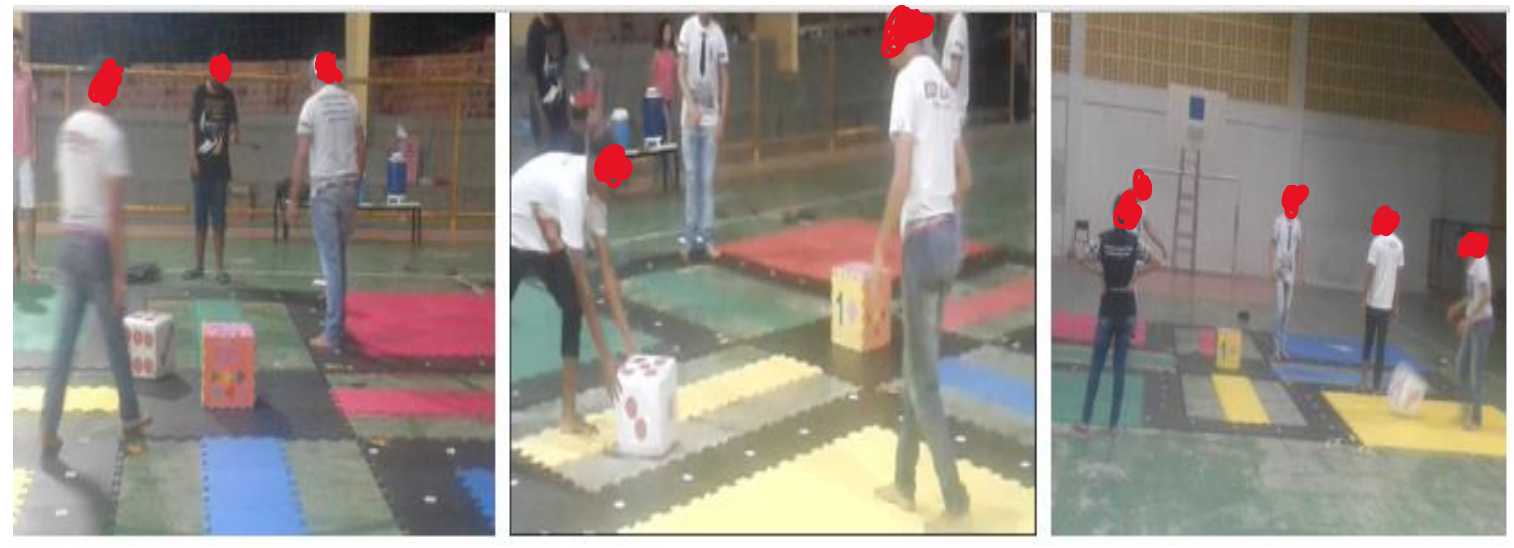

Fonte: Autoria própria.

\section{Culminacia do projeto}

No dia da culminância do projeto todas as turmas da escola participaram como competidoras e e estavam propensas ao espirito esportivo, visto que propomos iteração e cooperação dos alunos, com ampliação das situações. Nisso, percebemos alunos mais introvertidos - maior desprendimento e alegria. Ainda percebemos a superação - as dificuldades se transformaram em desafios de cada um deles em querem acertar as perguntas e assim vencer a competição, além da consciência e valorização de amizade, companheirismo e paciência para esperar a sua vez.

Como estávamos lidando com jovens de turmas diferentes separamos as disputas por série para que não houvesse desacordo com níveis de questões e perguntas que fugisse das modalidades de ensino. $\mathrm{O}$ tabuleiro foi montado na quadra do ginásio de esportes da instituição. Como se pode ver: 
Rev. Dimensão, Maceió, v. 5. n. 2, p. 7-20, jan/mar, 2021

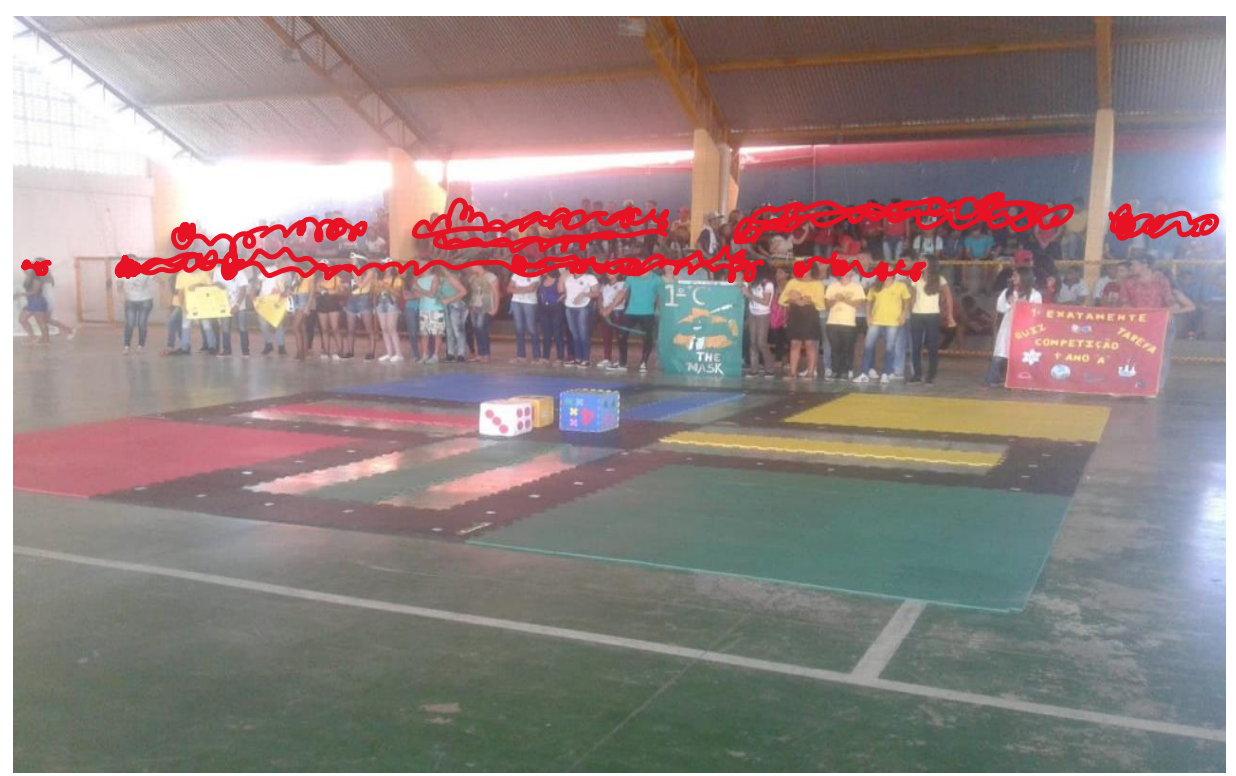

Fonte: Autoria própria.

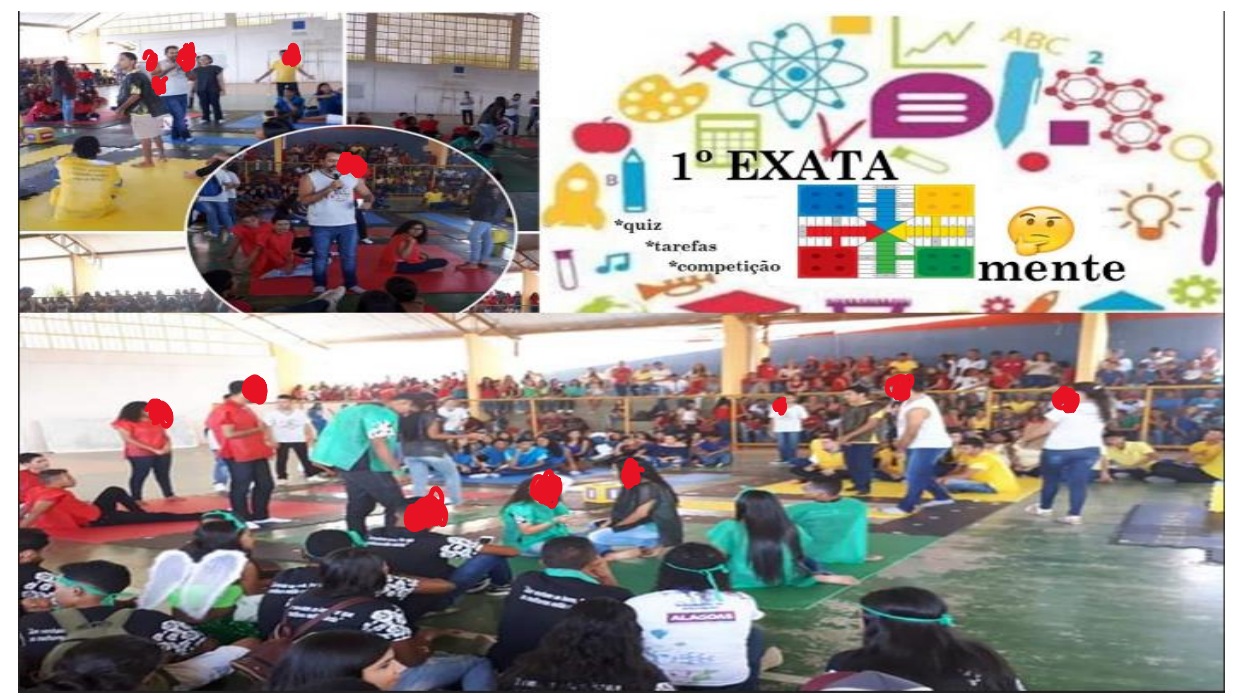

Fonte: Autoria própria. 


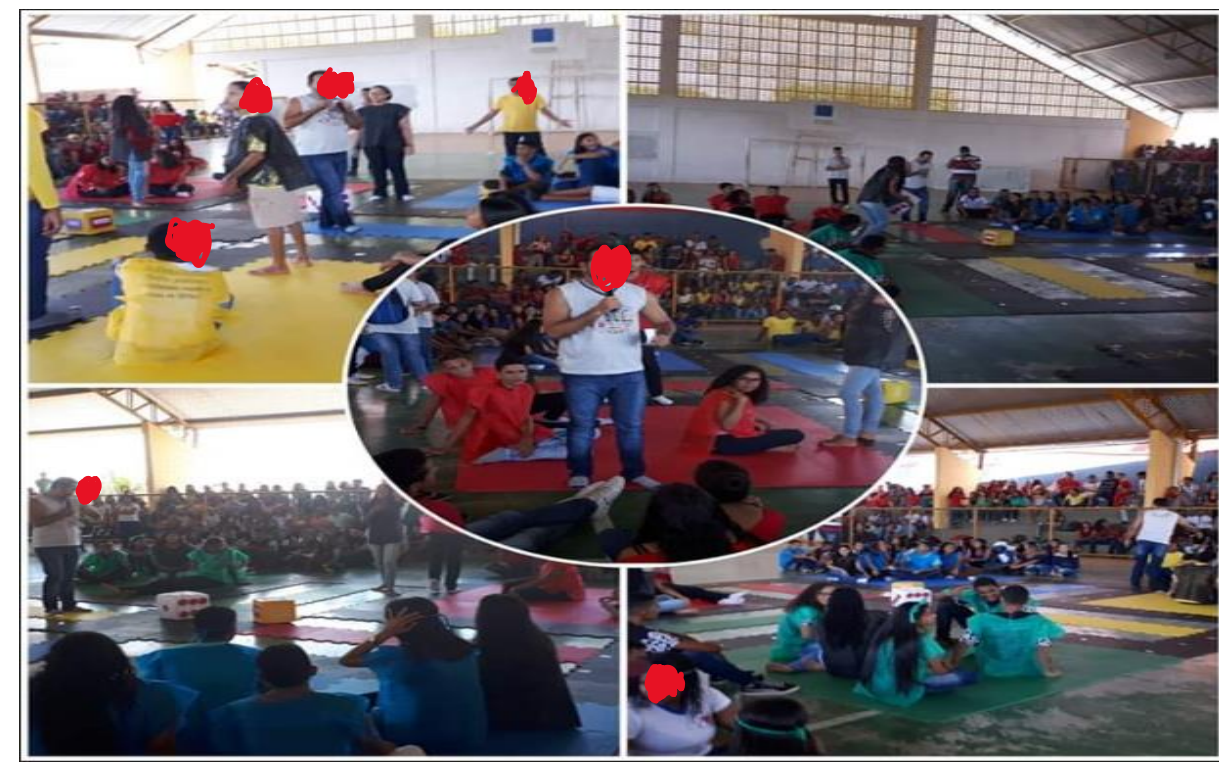

Fonte: Autoria própria.

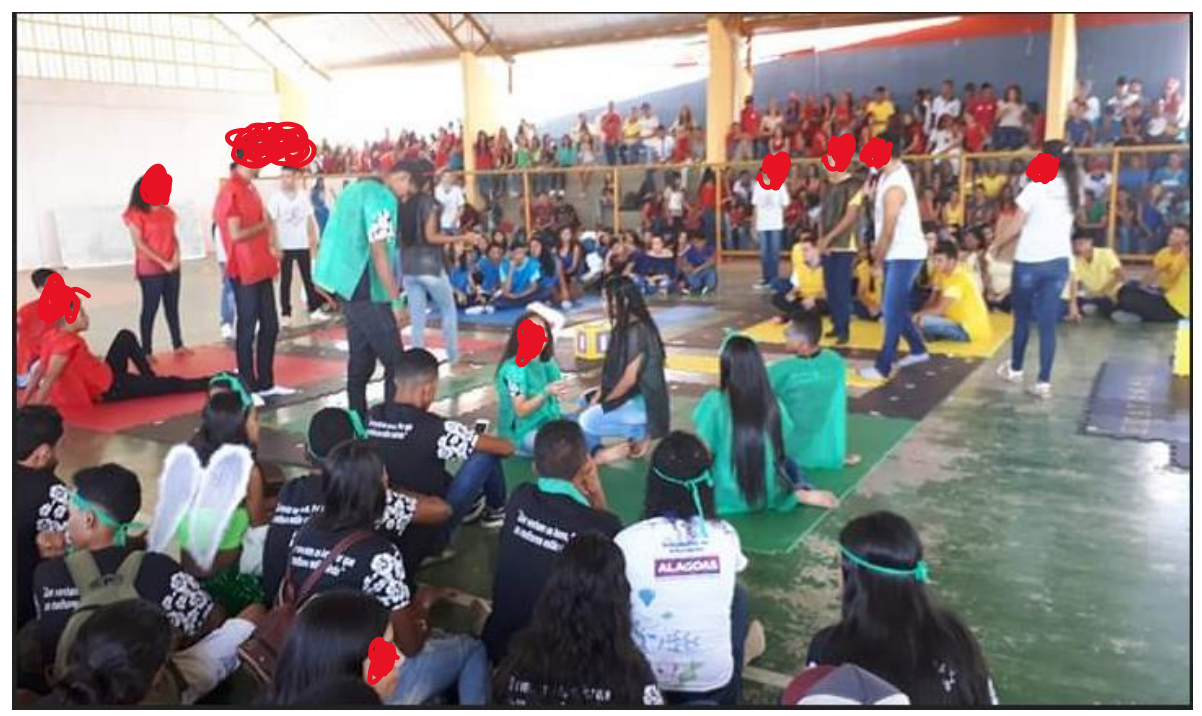

Fonte: Autoria própria.

\section{RESULTADOS E DISCURSÕES}

O projeto trouxe uma desenvoltura brilhante para os participantes e uma nova forma de propor e dinamizar o processo de ensino- aprendizagem, visto que a dinâmica proposta valeu-se de adquirir o aprendizado necessário e fazer com que os estudantes trocassem experiencias com os colegas de turmas e interagissem entre si, totalizando a busca pelo final da competição implementando os jogos de tabuleiro e eles servindo como peça, fazendo com que os alunos fossem agentes e peças fundamentais para a realização do projeto. Apesar das dificuldades encontradas percebemos que os alunos ficaram mais introspectivos com as ações que o jogo trazia fazendo-os interagir e buscar a grande vitória chegando no final. 


\section{CONSIDERAÇÕES FINAIS}

A percepção de que na dos computadores, do videogame e dos brinquedos eletrônicos percebemos que é possível despertar o interesse dos jovens estudantes por um simples tabuleiro, com números, charadas ou dicas, sem haver movimento ou imagens, trazendo-os a participação de atividades da escola e sobretudo dos jogos que julgam desnecessários e sem empolgação. Mas este senário mudou depois que viram e compreenderam a forma que ele estava

\section{REFERÊNCIAS}

GOMES, N. C. JOGOS DE TABULEIRO - UMA CONTRIBUIÇÃO LÚDICA NA APRENDIZAGEM E DESENVOLVIMENTO DO EDUCANDO. $3^{\circ}$ Congresso de boas práticas em sala de aula. set 2014 . Disponível em < https://ptdocz.com/doc/926866/jogos-detabuleiro-\%E2\%80\%93-umacontribui\%C3\%A7\%C3\%A3o1\%C3\%BAdica-na-aprendiza...>

NASCIMENTO, R. R.; NASCIMENTO, P. S. C. GAMIFICAÇÃ̃ PARA O ENSINO DE FÍSICA: O QUE FALAM AS PESQUISAS. Revista Vivências em Ensino de Ciências $3^{\text {a }}$ Edição Especial. Número 2 ISSN 2595 - 7597 https://periodicos.ufpe.br/revistas/vivenc ias.

SILVA et al. GAMIFICAÇÃO COMO ESTRATÉGIA DE APRENDIZAGEM ATIVA NO ENSINO DE FÍSICA. Revista brasileira de ensino de física. Vol.41. $\mathrm{n}^{\circ}$ 4. e20180309. 2019. Disponível em < sendo conduzido. $\mathrm{O}$ projeto interdisciplinar

- Exatamente - serviu de suporte as disciplinas de ciências da natureza abrangendo todos os conteúdos trabalhados em sala de aula e proporcionou a mais prazerosa atividade exitosa atribuída aos estudantes.

Usar um jogo humano foi uma tarefa muito desafiadora, mas muito proveitosa em seu conteúdo e etapas, permitindo que os alunos usassem sua capacidade física, intelectual e cognitiva, nas atividades propostas

https://www.scielo.br/pdf/rbef/v41n4/1806 -9126-RBEF-41-4-e20180309.pdf>

SILVA, G. K. B.; SILVA, B. G. K. GAMIFICAÇÃO: BENEFÍCIOS DA UTILIZAÇẪO DO JOGO DE TABULEIRO NO PROCESSO DE ENSINO-APRENDIZAGEM DAS AULAS DE ENSINO-APRENDIZAGEM DAS AULAS DE CIÊNCIAS. Congresso internacional de educação e tecnologias - Encontro de pesquisadores em educação a distância. CIET ENPED Jun/jul 2018. Disponível em< file:///C:/Users/genih/AppData/Local/Tem p/786-16-3658-1-10-20180521.pdf >

\section{GAROFALO, D. COMO AS}

\section{METODOLOGIAS ATIVAS} FAVORECEM O APRENDIZADO - A proposta é que o estudante esteja no centro do processo de aprendizagem. NOVA ESCOLA - Junho | 2018. Disponível em: $<$ https://novaescola.org.br/conteudo/11897 /como-as-metodologias-ativas-favorecemo-aprendizado> 